\title{
4. Human rights, childhood obesity and health inequalities
}

\author{
Marine Friant-Perrot ${ }^{1}$ and Nikhil Gokani ${ }^{2}$
}

\section{Introduction}

The prevalence of childhood obesity, and its rapid increase, is not distributed equally across populations. Some groups of children are more likely to live with obesity than others, with childhood obesity being strongly associated with belonging to a socioeconomic position group consuming more energy-dense diets. ${ }^{3}$ These health inequalities are largely systematic, and are mostly the result of the social, political and economic environment in which children live and play. ${ }^{4}$ These unfair differences in health outcomes not only mean that children from such groups have a higher chance of developing obesity, they are also likely to suffer worse consequences of obesity, and such obesity-related inequalities are likely to continue over the course of a child's life ${ }^{5}$ and thus also have harmful impacts on health, quality of life and life expectancy in their adult years. ${ }^{6}$

Despite the creation of a health-promoting environment for all children being recognized by the international community as a matter of societal responsibility, ${ }^{7}$ inequalities in childhood obesity are growing. ${ }^{8}$ Within legal frameworks, social, cultural and economic rights

\footnotetext{
${ }^{1}$ University of Nantes. Marine Friant-Perrot's contribution was translated from French by Anaëlle Chansay, PhD student at the University of Nantes.

${ }^{2}$ School of Law, University of Essex. I would like to thank Professor Chris Willet for his comments on an earlier draft.

${ }^{3}$ Y Wang and H Lim, 'The Global Childhood Obesity Epidemic and the Association Between Socio-Economic Status and Childhood Obesity' (2012) 24(3) International Review of Psychiatry 176.

${ }^{4}$ For high income countries, see for instance: DM Zarnowiecki, J Dollman and N Parletta, 'Associations Between Predictors of Children's Dietary Intake and Socioeconomic Position: A Systematic Review of the Literature' (2014) 15(5) Obesity Reviews 375. For low- and middle-income countries, see for instance: BM Popkin and MM Slining, 'New Dynamics in Global Obesity Facing Low- and Middle-Income Countries' (2013) 14(2) Obesity Reviews 11; SJ Ulijaszek, 'Inequality and Childhood Overweight and Obesity: A Commentary' (2017) 12(3) Pediatric Obesity 195.

5 A Palloni, 'Reproducing Inequalities: Luck, Wallets, and the Enduring Effects of Childhood Health' Demography 43(4) (2006) Demography 587; A Case et al, 'The Lasting Impact of Childhood Health and Circumstance' (2005) 24 Journal of Health Economics 365; PM Connell et al, 'How Childhood Advertising Exposure Can Create Biased Product Evaluations That Persist into Adulthood' (2014) 41 Journal of Consumer Research 119.

${ }^{6}$ JJ Reilly, 'Descriptive Epidemiology and Health Consequences of Childhood Obesity' (2005) 19(3) Best Practice \& Research Clinical Endocrinology \& Metabolism 327; JP Mackenbach, 'Socioeconomic Inequalities in Morbidity and Mortality in Western Europe' (1997) 349 Lancet 16551; A Case, A Fertig and C Paxson, 'The Lasting Impact of Childhood Health and Circumstance (2005) 24 Journal of Health Economics 365.

${ }^{7}$ See, for instance: WHO Global Action Plan on the Prevention and Control of NCDs 2013-2020 (WHO, 2013); Obesity and Inequities: Guidance for Addressing Inequities in Overweight and Obesity (WHO, 2014); Final Report of the WHO Commission on Ending Childhood Obesity (WHO, 2016).

${ }^{8}$ See for instance: LJ Johnson et al, 'Social Inequalities in Childhood Obesity: Trends, Determinants, and Interventions' in H Dele Davies et al (eds), Obesity in Childhood and Adolescence (2nd edn, ABC-CLIO, 2018); GK Singh, 'Trends and Contemporary Racial/Ethnic and Socioeconomic Disparities in US Childhood Obesity' in D Bagchi (ed), Global Perspectives on Childhood Obesity: Current Status, Consequences and Prevention (2nd edn, Elsevier, 2019); D Bann, 'Socioeconomic Inequalities in Childhood and Adolescent Body-Mass Index, Weight, and Height from 1953 to 2015: An Analysis of Four Longitudinal, Observational, British Birth Cohort Studies' (2018) 3(4) The Lancet Public Health PE194.
} 
are well placed to help reduce the prevalence of obesity. These human rights are inspired by the principle of solidarity and, as they are conceived as instruments of social transformation, they aim to provide corrective measures to economic liberalization. ${ }^{9}$ As their essence is to protect everyone equally, the reduction of health inequalities in childhood obesity can be articulated within this human rights discourse. In particular, through helping to restore a real capacity for choice in food consumption, and thereby supporting healthier diets for every child, the right to non-discrimination on the basis of socioeconomic status and the principle of equality can be thought of as a foundation for realizing social rights, in particular the right to health and the right to food.

Section 2 begins by demonstrating that the right to non-discrimination and the principle of equality are fundamental to the debates on reducing inequalities in childhood obesity. The section, firstly, argues that variations in socioeconomic factors, which lead to inequalities in childhood obesity, raise issues of discrimination; and should be seen as offending against the protections guaranteed by human rights instruments, and in particular the right to nondiscrimination in the Convention on the Rights of the Child as well as others rights which must be met without discrimination. The section, secondly, argues that the right to nondiscrimination is inherently connected with the principle of equality; and that the right to nondiscrimination should therefore be seen as seeking to promote equality of opportunity, and in particular the restoration of a genuine freedom for children to access nutritionally-balanced diets which can help prevent obesity.

Furthermore, as States must respect, protect and fulfil the rights of the child without discrimination on the basis of socioeconomic status, redirecting public policies towards greater emphasis on reducing inequalities in the process of preventing childhood obesity requires analysis of the available tools. Beyond the justiciability of protecting children from discrimination, there is a need to implement policies which transcend the simple procedural equality of the often-used method of providing all consumers with basic nutritional information, to acting more directly in limiting the harmful and inequitable effects of the food environment on children and their families.

Section 3, therefore, explores the implications of a human rights approach grounded in the right to non-discrimination on the basis of socioeconomic status and, more specifically, the opportunities in law for reducing health inequalities in childhood obesity prevention strategies. ${ }^{10}$ The section, firstly, explores the scope of the State's duties to respect, protect and fulfil the right to non-discrimination and the other rights which must be met without discrimination. The section, secondly, discusses the existing legal mechanisms used to prevent obesity, and the legal tools available to help reduce inequalities in childhood obesity. To this end, it argues that the currently favoured intervention of providing nutritional information is insufficiently effective, promotes inequalities and exacerbates discrimination. It therefore calls for State implementation of restrictions on the marketing of unhealthy food

\footnotetext{
9 See for instance: C Wellman, 'Solidarity, the Individual and Human Rights' (2000) 22(3) Human Rights Quarterly 639.

${ }^{10}$ A Child Rights-Based Approach to Food Marketing: A Guide for Policy Makers (UNICEF, 2018).
} 
to children as an evidence-based method to reduce inequalities and help better fulfil children's right to non-discrimination and protect them from unnecessary commercial influences. ${ }^{11}$

These issues have not been the subject of a comprehensive exploration in the literature. ${ }^{12}$ Some academics have drawn connections between health inequalities and human rights generally; ${ }^{13}$ or between health inequalities and other specific rights, such as the right to health. ${ }^{14}$ Others have sought to develop the right to non-discrimination generally; ${ }^{15}$ or more specifically in relation to other concerns. ${ }^{16}$ However, there have been few attempts to understand the link between health inequalities and the right to non-discrimination. ${ }^{17}$ Moreover, within the literature which has begun to attempt this, ${ }^{18}$ there has not been an attempt to look at childhood obesity, healthy diets, nutritional information and the Convention on the Right of the Child. This chapter, therefore, develops the literature in several respects. Firstly, this chapter contributes to the understanding of the right to non-discrimination both generally and as expressed in the Convention on the Rights of the Child. Secondly, it develops a deeper understanding of the link between the right to non-discrimination and health inequalities. Thirdly, it adds to the literature an understanding of the role of the right to non-discrimination and the principle of equality as they apply to inequalities in childhood obesity. Fourthly, it adds to the literature an exploration of the role of unhealthy food marketing restrictions as a tool in helping to move closer to fulfilling the child's right to nondiscrimination. Fifthly, through the specific study on nutritional information, the chapter

\footnotetext{
11 'Unhealthy food' refers to nutritiously poor food and non-alcoholic beverages that are high in fats, sugar or salt. This follows the World Health Organization: 'Set of Recommendations on the Marketing of Foods and Non-Alcoholic Beverages to Children' (WHO, 2010).

${ }^{12}$ But see shorter earlier work by one or both of the co-authors of this chapter: A Child Rights-Based Approach to Food Marketing: A Guide for Policy Makers (UNICEF, 2018); A Garde, N Gokani and M Friant-Perrot 'Children's Rights, Childhood Obesity and Health Inequalities' (2018) 43 UNSCN News 65.

${ }^{13}$ See for instance: P Hunt and G Backman, 'Health Systems and the Right to the Highest Attainable Standard of Health' (2008) 10(1) Health and Human Rights 81; JK Burns, 'Mental Health And Inequity: A Human Rights Approach to Inequality, Discrimination, and Mental Disability' (2009) 11(2) Health and Human Rights 19; RA Atuguba, 'Equality, Non-Discrimination and Fair Distribution of the Benefits of Development' in Realizing the Right to Development (United Nations, 2013).

${ }^{14}$ JP Ruger, 'Toward a Theory of a Right to Health: Capability and Incompletely Theorized Agreements' (2006) 18(2) Yale Journal of Law \& The Humanities 3.

${ }^{15}$ See for instance: B Abramson, Article 2: The Right of Non-Discrimination (Martinus Nijhoff Publishers, 2008).

${ }^{16}$ See for instance: K Stronks et al, Social Justice and Human Rights as a Framework for Addressing Social Determinants of Health. Final Report of the Task Group on Equity, Equality and Human Rights Review of Social Determinants of Health and the Health Divide in the WHO European Region (WHO, 2016).

${ }^{17}$ For the few non-legal papers trying to link discrimination with health inequalities see for instance: $\mathrm{P}$

Braveman and S Gruskin, 'Defining Equity in Health' (2003) 57 Journal of Epidemiology and Community Health 254.

${ }^{18}$ For the few attempts see: G MacNaughton, 'Untangling Equality and Non-Discrimination to Promote the Right to Health Care for All' (2009) 11(2) Health and Human Rights 47; P Braveman, 'Social Conditions, Health Equity, and Human Rights' (2010) 12(2) Health and Human Rights 31; AR Chapman, 'The Social Determinants of Health, Health Equity, and Human Rights' (2010) 12(2) Health and Human Rights 17.
} 
further develops the broader literature on behavioural economics ${ }^{19}$ and the limits of consumer empowerment by information. ${ }^{20}$

\section{Inequalities in childhood obesity and social justice}

Health inequalities, sometimes known as health inequities, ${ }^{21}$ are the differences in health between groups of individuals ${ }^{22}$ which are systematic, socially produced (and therefore modifiable) and unfair. ${ }^{23}$ At all geographical levels, both within and between countries, there is clear evidence that some groups of children live with worse health outcomes than other groups of children. ${ }^{24}$

More specifically, health inequalities in childhood obesity are strongly associated with belonging to a socioeconomic position ${ }^{25}$ group consuming more energy-dense diets. ${ }^{26}$ In high income countries, there is an inverse association between the socioeconomic position of a child and his or her obesity status. ${ }^{27}$ This is amplified in some groups, especially in relation to ethnicity, ${ }^{28} \operatorname{sex}^{29}$ and other family circumstances. ${ }^{30}$ In low- and middle-income countries,

\footnotetext{
${ }^{19}$ See for instance: D Kahneman, P Slovic and A Tversky, Judgment under Uncertainty: Heuristics and Biases (Cambridge University Press, 1982); A Tversky and D Kahneman, 'Judgment under Uncertainty: Heuristics and Biases' (1974) 185(4157) Research 1124; M Rabin 'Psychology and Economics' (1998) 36(1) Journal of Economic Literature 11.

${ }^{20}$ See for instance: G Howells, 'The Potential and Limits of Consumer Empowerment by Information' (2005) 32 Journal of Law and Society 349; C Willett, 'Re-Theorising Consumer Law' (2018) 77(1) Cambridge Law Journal 179; GK Hadfield, R Howse and MJ Trebilcock, 'Information-Based Principles for Rethinking Consumer Protection Policy' (1998) 21 Journal of Consumer Policy 131.

${ }^{21}$ It should be noted that, in a strict sense, inequalities refer to the generic differences in health; whereas inequities are those inequalities which are also systematic, socially produced and unfair. Whereas inequalities are factual statements, and inequities normative statements which demands regulatory action as a matter of social justice, this distinction is not always used. The terms are commonly used interchangeably to refer to the narrower definition of inequities. Following the wider literature, the remainder of this paper uses the phrase 'health inequalities' as synonymous with the more accurate 'health inequities'.

${ }^{22}$ I Kawachi, S V Subramanian and N Almeida-Filho, 'A Glossary for Health Inequalities' (2002) 56 Journal of Epidemiology \& Community Health 647, 647.

${ }^{23}$ M Whitehead and G Dahlgren, 'Concepts and Principles for Tackling Social Inequities in Health: Levelling Up Part 1' (WHO Regional Office for Europe, 2007).

${ }^{24}$ See for instance: M Marmot, 'Social Determinants of Health Inequalities' (2005) 365 Lancet 1099.

${ }^{25}$ Socioeconomic position is a description of the social hierarchy or ranking of individuals or groups based on sociological and economic goods. It is used here to refer to social status in its widest sense, including factors which may not traditionally be considered to relate to socioeconomic status, such as gender, sexuality and ethnicity. There are many other definitions, and indeed the use of socioeconomic position is in itself not universal, but the concept aims 'to capture an individual's or group's access to the basic resources required to achieve and maintain good health': VL Shavers, 'Measurement of Socioeconomic Status in Health Disparities Research' (2007) 99(9) Journal of the National Medical Association 1013, 1013.

${ }^{26}$ Y Wang and H Lim, 'The Global Childhood Obesity Epidemic and the Association between Socio-Economic Status and Childhood Obesity' (2012) 24(3) International Review of Psychiatry 176.

${ }^{27}$ DM Zarnowiecki, J Dollman and N Parletta, 'Associations Between Predictors of Children's Dietary Intake and Socioeconomic Position: A Systematic Review of the Literature' (2014) 15(5) Obesity Reviews 375.

${ }^{28}$ AM El-Sayed et al, 'Ethnic Inequalities in Obesity Among Children and Adults in the UK: A Systematic Review of the Literature' (2011) Obesity Reviews e517; T Olds et al, 'Evidence That the Prevalence of Childhood Overweight is Plateauing: Data from Nine Countries' (2011) 6 International Journal of Pediatric Obesity 342; S Kumanyika, et al, 'Community Energy Balance: A Framework for Contextualizing Cultural Influences on High Risk of Obesity in Ethnic Minority Populations' (2012) 55 Preventive Medicine 371; J Brug et al, 'Differences in Weight Status and Energy-Balance Related Behaviours According to Ethnic Background
} 
childhood obesity is linked with factors of both higher socioeconomic position, such as increased wealth, and lower socioeconomic position, such as lower levels of education and maternal malnutrition during gestation. ${ }^{31}$

While childhood obesity largely results from an energy imbalance, its development follows a complex, multifactorial pathway. This pathway largely begins with the child's exposure to an unhealthy environment, followed by the child's behavioural response to that environment and, in turn, the child's biological response. Differences in the environment - such as greater promotion and availability of cheaper, energy-dense, unhealthy food - lead to variations in behaviours and biological responses. These environmental factors are known as the social determinants of health ${ }^{32}$ and are responsible for many of the differences in rates of obesity between groups. ${ }^{33}$ Not only do child members of socioeconomic groups consuming energydense diets have a higher chance of developing obesity, members of these groups are also likely to suffer worse consequences of obesity. Such obesity-related inequalities are likely to continue over the course of a child's life ${ }^{34}$ and thus also have a harmful impact on health, quality of life and life expectancy in their adult years. ${ }^{35}$ It follows that creating a healthpromoting environment for all children is recognized by the international community as a matter of societal responsibility. ${ }^{36}$

This section seeks to show that the right to non-discrimination and the principle of equality are fundamental to the debates on reducing inequalities in childhood obesity. This section, firstly, argues that variations in socioeconomic factors offend the protections guaranteed by

among Adolescents in Seven Countries in Europe: The ENERGY-Project' (2012) 7 Pediatric Obesity 399; N Gupta et al, 'Childhood Obesity in Developing Countries: Epidemiology, Determinants and Prevention' (2012) 33 Endocrine Reviews 48.

${ }^{29}$ J Sobal and AJ Stunkard, 'Socioeconomic Status and Obesity: A Review of the Literature' Psychological Bulletin 105(2) (1989) 260; L McLaren, 'Socioeconomic Status and Obesity' (2007) 29 Epidemiologic Reviews 29; M Jodkowska et al, 'Overweight and Obesity Among Adolescents in Poland: Gender and Regional Differences’ (2010) 13 Public Health Nutrition 1688.

${ }^{30} \mathrm{~S}$ Robinson et al, 'A Narrative Literature Review of the Development of Obesity in Infancy and Childhood' Journal of Child Health Care (2012) 16(4) Journal of Child Health Care 339; G Tabacchi et al, 'A Review of the Literature and a New Classification of the Early Determinants of Childhood Obesity: From Pregnancy to the First Years of Life' (2007) 27 Nutrition Research 587; S Garasky, 'Family Stressors and Child Obesity' (2009) 38 Social Science Research 755.

${ }^{31}$ BM Popkin and MM Slining, 'New Dynamics in Global Obesity Facing Low- and Middle-Income Countries' (2013) 14(2) Obesity Reviews 11; SJ Ulijaszek, 'Inequality and Childhood Overweight and Obesity: A Commentary' (2017) 12(3) Pediatric Obesity 195.

${ }^{32}$ Commission on Social Determinants of Health, 'Closing the Gap in a Generation: Health Equity through Action on the Social Determinants of Health' (WHO, 2008), 1.

${ }^{33}$ MK Campbell, 'Biological, Environmental, and Social Influences on Childhood Obesity' (2015) 79(1-2) Pediatric Research 205.

34 A Palloni, 'Reproducing Inequalities: Luck, Wallets, and the Enduring Effects of Childhood Health' Demography 43(4) (2006) Demography 587; A Case et al, 'The Lasting Impact of Childhood Health and Circumstance' (2005) 24 Journal of Health Economics 365; PM Connell et al, 'How Childhood Advertising Exposure Can Create Biased Product Evaluations That Persist into Adulthood' (2014) 41 Journal of Consumer Research 119.

35 JJ Reilly, 'Descriptive Epidemiology and Health Consequences of Childhood Obesity' (2005) 19(3) Best Practice \& Research Clinical Endocrinology \& Metabolism 327; JP Mackenbach, 'Socioeconomic Inequalities in Morbidity and Mortality in Western Europe' (1997) 349 Lancet 16551; A Case, A Fertig and C Paxson, 'The Lasting Impact of Childhood Health and Circumstance (2005) 24 Journal of Health Economics 365.

${ }^{36}$ Above n7. 
human rights instruments, and in particular the right to non-discrimination in the Convention on the Rights of the Child (CRC) as well as other rights which must be met without discrimination. While health inequalities have been linked with human rights generally ${ }^{37}$ or linked with other specific rights, ${ }^{38}$ this section goes beyond this work by developing the link between health inequalities and the right to non-discrimination. ${ }^{39}$ It further adds to the literature an understanding of these issues in relation to the CRC, and in doing so also contributes to a better understanding of the right to non-discrimination more broadly. ${ }^{40}$ This section, secondly, argues that the right to non-discrimination is inherently connected with the principle of equality; and that the right to non-discrimination therefore seeks to promote equality of opportunity, and in particular the restoration of a genuine freedom for children to access nutritionally-balanced diets which are not associated with obesity. In doing so, this section adds to the literature an understanding of the role of the right to non-discrimination and the principle of equality in relation to inequalities in childhood obesity, and in doing so also helps develops the existing literature on substantive equality. ${ }^{41}$

\subsection{Inequalities and non-discrimination}

The social determinants of health, and therefore the variations in environments in which children live, raise issues of discrimination. The right to non-discrimination is granted in most national legal orders and is specifically recognized in almost all international human rights instruments. Its importance is seen through its inclusion in the second Article of the Universal Declaration of Human Rights (UDHR), the International Covenant on Civil and Political Rights (ICCPR), the International Covenant on Economic, Social and Cultural Rights (ICESCR), and the Convention on the Rights of the Child (CRC). Article 26 ICCPR in particular recognizes the right to non-discrimination in conjunction with the right to health and the right to food.

The CRC, through its aim to protect children from behaviours and circumstances that 'offend the human dignity of the child', ${ }^{42}$ further acknowledges 'that children are born with fundamental freedoms and the inherent rights of all human beings and should not be discriminated against because they are children'. ${ }^{43}$ The CRC does not itself provide a definition of discrimination, and neither is there a General Comment from the Committee on the Rights of the Child addressing discrimination specifically. Analysis of the General Comments of the Human Rights Committee, however, reveals that discrimination implies

\footnotetext{
${ }^{37}$ Above n13.

${ }^{38}$ Above n14.

${ }^{39}$ Above n18.

40 Above n15.

${ }^{41}$ See for instance: S Fredman, 'Substantive equality revisited' (2016) 14(3) International Journal of Constitutional Law 712.

${ }^{42}$ Committee on the Rights of the Child, 'General Comment No. 1: The aims of education', CRC/GC/2001/1, United Nations, 17 April 2001, [10].

${ }^{43}$ F Sheahan, 'Translating the Right to Non-Discrimination into Reality' (Save the Children Sweden, 2008 ), 9. See also: Article 2 in the UDHR, ICCPR and ICESCR.
} 
differentiation of similar situations, based on protected characteristics, which impairs the child's enjoyment of rights. ${ }^{44}$ This notion of discrimination is interpreted broadly. It includes circumstances and behaviours which are overtly discriminatory, and also policies which are discriminatory in a covert or hidden manner. ${ }^{45}$ Discrimination also includes policies which have the purpose of discrimination, and also the effect or outcome of discrimination whether or not discrimination is intended. Moreover, discrimination can be the result of both laws or the result of systematic patterns of behaviours.

It is argued, therefore, that protecting children from discrimination that is caused by, and reinforced through, the social determinants of health falls within the duties of States. Under the right to non-discrimination enshrined in Article 2 ICESCR, as interpreted in General Comment 20 of the Committee on Economic, Social and Cultural Rights, States must contribute to the reduction of discrimination faced by vulnerable socioeconomic groups. ${ }^{46}$ The list of grounds of discrimination listed in Article 2(2) ICESCR is very broad and the reference to 'any other characteristics' includes any form of differentiated treatment that does not have a reasonable and objective justification. ${ }^{47}$ Paragraph 35 of General Comment 20, which interprets this provision, considers that '[i]ndividuals and groups of individuals must not be arbitrarily treated on account of belonging to a certain economic or social group or strata within society'. ${ }^{48}$ Regarding children's vulnerability to malnutrition, the reference to Article 2 ICESCR must be combined with the rules laid down in the CRC which protects children from discrimination in three different ways.

First, Article 2(1) of the CRC provides protection as it recognizes non-discrimination as a guiding principle. ${ }^{49}$ It prohibits discrimination against children in respect of each of the other specific rights provided under the CRC. Discrimination under Article 2(1) is prohibited if is based on the protected characteristics of the child or their parents, guardians or families. These characteristics include the many social determinants of health which childhood obesity is associated with, including race, sex, religion, social origin, disability and other status. 'Other status' here has been interpreted to include a child's health status. ${ }^{50}$ General Comment 20 further establishes that children cannot be discriminated against on the basis of socioeconomic position in the exercise of their right to health. ${ }^{51}$ Yet, disaggregated data

\footnotetext{
${ }^{44}$ Human Rights Committee, 'General Comment No. 18: Non-Discrimination' (Thirty seventh session, 1989) HRI/GEN/1/Rev.9 (Vol. I) pp 195-198, [7]. But see [13], where the Committee noted that 'not every differentiation of treatment will constitute discrimination, if the criteria for such differentiation are reasonable and objective and if the aim is to achieve a purpose which is legitimate under the Covenant.', and which is a point repeated by the CRC Committee in General Comment 20, [21].

${ }^{45}$ Above n42, [1].

${ }^{46}$ Committee on Economic, Social and Cultural Rights, 'General Comment No, 20, Non-discrimination in economic, social and cultural rights’, E/C.12/GC/20, 2 July 2009.

47 Above n46, [27].

${ }^{48}$ Above n46.

49 See: United Nations, 'Report of the Committee on the Rights of the Child', Supplement No. 41 (A/57/41) 2002, [38].

50 'Other' characteristics must be interpreted broadly so as to be sufficiently similar to the explicit characteristics. This would include the child's status of being overweight or obese: Committee on the Rights of the child, General Comment No. 3 (2003) HIV/AIDS and the rights of the child, CRC/GC/2003/1, [5] - where the Committee included HIV/AIDS status as being within 'other status' for the purposes of Article 2(1).

${ }^{51}$ Above n46.
} 
reveal that children from lower socioeconomic groups live more with the major unhealthy risk factors of unhealthy diets and reduced physical activity. ${ }^{52}$

It is submitted, therefore, that the child shall not be discriminated against in their right to the enjoyment of the highest attainable standard of health contained in Article 24 of the CRC, and to the right to a standard of living adequate for the child's physical, mental, spiritual, moral and social development set out in Article 27. The right to health in particular is almost universally recognized by all human rights texts, and is defined in the UDHR to include food, clothing, housing, medical care and necessary social services, with the special provision of assistance being required in childhood (Article 25). The right has evolved significantly, particularly with the general comments of the Committee on Economic, Social and Cultural Rights, ${ }^{53}$ which, for instance, stated in General Comment No. 14 that the right to health includes access to nutritionally adequate food. Similarly, helped through the action of the UN Special Rapporteur on the Right to Food, ${ }^{54}$ the normative content of the right to an adequate standard of living is interpreted broadly to include 'the right to have regular, permanent and free access, either directly or by means of financial purchases, to quantitatively and qualitatively adequate and sufficient food corresponding to the cultural traditions of the people to which the consumer belongs, and which ensures a physical and mental, individual and collective, fulfilling and dignified life free of fear. ${ }^{55}$

Secondly, Article 2(2) of the CRC prohibits unreasonable discrimination and punishment in all parts of the child's life, regardless of whether specific protection is afforded elsewhere in the CRC. Discrimination is prohibited in respect of the status, activities, and expressed opinions or beliefs of the child's parents, guardians or family. Therefore, inequalities resulting from discrimination on the basis of household income, education, access to economic goods and other similar factors should also be considered prohibited.

Thirdly, several articles in the CRC provide more specific protection. This includes the protection of children with disabilities. Not only are obese children more likely to face

\footnotetext{
${ }^{52}$ Various studies and reviews have confirmed these findings. See for instance C Knai et al, 'Socioeconomic Patterning of Childhood Overweight Status in Europe' (2012) 9 International Journal of Environmental Research and Public Health 1472; G Tabacchi et al, 'A Review of the Literature and a New Classification of the Early Determinants of Childhood Obesity: From Pregnancy to the First Years of Life' (2007) 27 Nutrition Research 587; DM Zarnowiecki et al, 'Associations Between Predictors of Children's Dietary Intake and Socioeconomic Position: A Systematic Review of the Literature' (2014) 15 Obesity Reviews 375; V Shrewsbury and J Wardle, 'Socioeconomic Status and Adiposity in Childhood: A Systematic Review of Cross-sectional Studies 1990-2005' (2008) 16(2) Obesity 275; SF Weng, 'Systematic Review and Meta-Analyses of Risk Factors for Childhood Overweight Identifiable During Infancy' (2012) 97 Archives of Disease in Childhood 1019; Y Wang and H Lim, 'The Global Childhood Obesity Epidemic and the Association Between SocioEconomic Status and Childhood Obesity' (2012) 24(3) International Review of Psychiatry 176.

${ }^{53} \mathrm{M}$ Trilsch, 'La Judiciarisation du Droit à la Santé: Quelles Perspectives pour la Procédure de Communications Individuelles devant le Comité des Droits eEconomiques, Sociaux et Culturels?' (2015) 57(1) Revue de Droit International et de Croit Comparé 43.

${ }^{54}$ W Barth Eide, 'From Food Security to the Right to Food' in W Barth Eide and U Kracht Antwerpen (eds), Food and Human Rights in Development, Volume I: Legal and Institutional Dimensions and Selected Topics (Intersentia, 2005); J Ziegler et al, The Fight for the Right to Food: Lessons Learned (Palgrave Macmillan, 2011).

${ }^{55}$ Commission on Human Rights, 'The Right to Food. Report by the Special Rapporteur on the Right to Food, Mr. Jean Ziegler', E/CN.4.2001.53, [14].
} 
adverse consequences in life as a result of their health, including stigmatization, ${ }^{56}$ in some circumstances obesity may be classified as a disability, ${ }^{57}$ and thus, it is argued, requiring States to ensure that such a child enjoys 'a full and decent life, in conditions which ensure dignity, promote self-reliance and facilitate the child's active participation in the community' (Article 23). ${ }^{58}$

\subsection{Non-discrimination and equality}

The right to non-discrimination gives rise to important obligations on the State. There is an obligation to eliminate discrimination on the basis of socioeconomic position and eradicate discrimination in children's exercise of their rights to health and food on this basis.

Nevertheless, even if we consider these fundamental rights as potential levers to tackle inequalities in childhood obesity, it should be noted that they have so far been insufficiently mobilized. When litigated, these rights have been successful in reducing inequalities in terms of food security and the fight against undernutrition. In 2007, for instance, the right to food in the ICESCR was successfully argued as protecting indigenous people in Argentina to help create more equitable distribution of food and subsidies. ${ }^{59}$ Similarly, in 2010 in Germany, in a case where the law resulted in a 14-year-old teenager receiving nutrition equivalent to a newborn and only $60 \%$ of what an adult received, the right to health and the right to dignity proved meritorious arguments for vulnerable citizen to claim a higher minimum level of subsistence to ensure sufficient nutrition. ${ }^{60}$

Even in the relatively few examples of cases where inequalities have been successfully challenged, individual or collective actions such as litigation have been difficult to initiate, support and fund. With the justiciability of these rights not sufficiently established to make legal actions necessarily successful, these rights have not yet reached a level where they can universally be invoked in proceedings to reduce health inequalities. Moreover, the lack of clarity has sometimes resulted in outcomes which may actually increase gaps in health outcomes. For instance, in Brazil, the State was required to provide expensive medical surgery if it was necessary to preserve human health, even though this was likely to benefit only the most informed citizens of higher socioeconomic groups and therefore did not give

\footnotetext{
${ }^{56}$ M Hartlev, 'Stigmatisation as a Public Health Tool against Obesity: A Health and Human Rights Perspective' European Journal of Health Law (2014) 21(4) 365; I Janssen et al, 'Associations Between Overweight and Obesity with Bullying Behaviors in School-Aged Children' (2004) 113(5) Pediatrics 1187.

${ }^{57}$ See for example: Court of Justice of the European Union, Case C-354/13, Fag og Arbejde v Kommunernes Landsforening ECLI:EU:C:2014:2463, [53].

${ }^{58}$ A Child Rights-Based Approach to Food Marketing: A Guide for Policy Makers (UNICEF, 2018).

${ }^{59}$ Supreme Court of Argentina, Case of Defensor del Pueblo c. Estado Nacional y otra sept 18, 2007, D.587, XLIII.

${ }^{60}$ Cour const., BVerfGE, 9 fév. 2010, Hartz IV, RDSS, 2010, p. 653, note Céline FERCOT.
} 
sufficient regard to the equitable distribution of expenditure within the broader healthcare system. ${ }^{61}$

Part of this difficulty in making better use of the right to non-discrimination results from the right sometimes being conceptualised as a negative right leading to formal equality in law. Formal equality is rooted in consistency and rationality: comparable situations must not be treated differently, and different situations must not be treated in the same way. This seemingly fair construction, however, hides its limited utility in tackling the causes of inequality - there is an assumption that pre-existing norms are inherently neutral. This incomprehension of context fails to lead to equality of opportunity and does not address the legacy of disadvantage.

Human rights law has traditionally made slow progress in moving away from viewing nondiscrimination as a negative right to formal equality towards viewing it as a positive right to substantive equality. ${ }^{62}$ Substantive equality, often captured through the principle of equality, ${ }^{63}$ views non-discrimination, in part, by taking the focus away from individualistic factors towards more focus on the group collective experiences of inequality. This accepts that discrimination is not random but instead predominantly experienced by individuals sharing similar characteristics. ${ }^{64}$ The principle of equality seeks to redress disadvantage, enhance participation, address stigma, accommodate difference and achieve structural change. Substantive equality, therefore, requires the adoption of measures intended to promote equality of opportunity when opportunities are significantly threatened. ${ }^{65}$ It is posited that this implies equal access to a healthy diet. To ensure that children are empowered to control their own health to prevent obesity, they should be granted, on equal terms, genuine access to healthy food. Conversely, they must not be subjected to negative influences leading to an unhealthy diet. Granting equal access to healthy food implies a challenge to the food environment and the food environment's role in the development of nutrition-based diseases. Public health and nutrition policies should aim to improve not only individual determinants of eating habits but also act on environmental determinants. ${ }^{66}$

\footnotetext{
${ }^{61} \mathrm{~J}$ Tobin, The Right to Health in International Law (Oxford University Press, 2012); O Ferraz, 'The Right to Health in the Courts of Brazil: Worsening Health Inequities?' (2009) 11 Health \& Human Rights 33.

${ }^{62}$ See further: G MacNaughton, 'Untangling equality and non-discrimination to promote the right to health care for all' (2009) 11 Health and Human Rights 47; S Fredman, 'Combating Racism with Human Rights: The Right to Equality' in S Fredman (ed), Discrimination and Human Rights: The Case of Racism (Oxford University Press, 2001).

${ }^{63}$ It should be noted that some academics have argued that there is a right to equality. However, such a position is insufficiently developed and not universally accepted, and therefore this chapter maintains the distinction between the right to non-discrimination and the principle of equality.

${ }^{64}$ Mark Bell, Racism and Equality in the European Union (Oxford University Press, 2008), ch 2.

${ }^{65}$ S Fredman, 'Substantive equality revisited' (2016) 14(3) International Journal of Constitutional Law 712.

${ }^{66} \mathrm{R}$ Mc Gill et al, 'Are Interventions to Promote Healthy Eating Equally Effective for All? Systematic Review of Socioeconomic Inequalities in Impact' (2015) 15 BMC Public Health 457; M White et al, 'How and Why Do Interventions That Increase Health Overall Widen Inequalities Within Populations?' in SJ Babones (ed), Social Inequality and Public Health (Policy Press, 2009), 64-81; N Larson and M Story, 'A Review of Environmental Influences on Food Choices' (2009) 38 (suppl 1) Annals of Behavioral Medicine S56. See further for example: Final report of the WHO Commission on Ending Childhood Obesity (WHO, 2016); Obesity and Inequities: Guidance for Addressing Inequities in Overweight and Obesity (WHO Regional Office for Europe 2014); EU Action Plan on Childhood Obesity 2014-2020 (European Union, 2014), 11.
} 
Furthermore, to ensure that individuals can choose their diet on equal terms, it is necessary to restore genuine freedom of choice by ensuring a capacity or capability ${ }^{67}$ for individuals to access a nutritionally-balanced diet. That is to say that one's choice of diet should not be purely theoretical but actually be achievable by all. Equal access to food for the entire population entails rethinking of freedom as the substantive empowerment of individuals, regardless of their environment and resources, to actually have access to healthy food. This allows the preservation of a genuine capacity of choice for children and their families, and supports healthier diets within economic resources and in accordance with their circumstances and backgrounds. Yet this must not lead to the standardization of diets. Between nature and culture, food does not simply boil down to a level of calories. The equation is complex because it is necessary to ensure equal access to food in sufficient nutritional quality and quantity while preserving cultural specificities. Inequalities should be reduced by law without limiting disparities: equality must exist in diversity - a point which has been upheld by the Human Rights Council. ${ }^{68}$

\section{Realization of equality by States}

The right to non-discrimination and the principle of equality can both support the implementation of interventions to reduce health inequalities in childhood obesity. Tackling these inequalities requires, as a prerequisite, an understanding of the causes of the stratification of health outcomes across socioeconomic groups, as highlighted above. However, while some of the necessary and sufficient conditions involved in causation, and variation in patterning, of childhood obesity can be identified, this is largely based on correlation, not causation. ${ }^{69}$ Without a complete model on behavioural risk in this patterning, ${ }^{70}$ the options for prevention are for States to, most fundamentally, reduce inequalities in the distribution of socioeconomic factors and structural determinants, and then to tackle specific or intermediary determinants which mediate the effect of socioeconomic position on health, ${ }^{71}$ such as the marketing of unhealthy food to children.

This section seeks to demonstrate the implications of following a human rights approach grounded in the right to non-discrimination on the basis of socioeconomic status and, more specifically, the opportunities in law for reducing health inequalities in childhood obesity

\footnotetext{
${ }^{67}$ A Sen, The Idea of Justice (Penguin Books, 2009).

${ }^{68}$ Human Rights Council Thirty-third session Agenda item 5 Human rights bodies and mechanisms Right to health and indigenous peoples with a focus on children and youth Study by the Expert Mechanism on the Rights of Indigenous Peoples A/HRC/33/57, [48].

${ }^{69}$ J Bonnefoy et al, 'Constructing the evidence base on the social determinants of health: A guide' (NICE 2007), 14.

${ }^{70}$ On existing models see for instance G McCartney, C Collins and M Mackenzie, 'What (or Who) Causes Health Inequalities: Theories, Evidence and Implications?' (2013) 113 Health Policy 221; G Scambler, 'Health Inequalities' (2012) 34(1) Sociology of Health \& Illness 130.

${ }^{71}$ H Graham, 'Social Determinants and Their Unequal Distribution: Clarifying Policy Understandings' (2004) 82(1) Milbank Quarterly 101; H Graham, 'Intellectual Disabilities and Socioeconomic Inequalities in Health: An Overview of Research' (2005) 18 Journal of Applied Research in Intellectual Disabilities 101. See also 'Closing the Gap in a Generation: Health Equity Through Action on the Social Determinants of Health’ (WHO, 2008).
} 
prevention strategies. First, we explore the scope of the State's duties to respect, protect and fulfil the right to non-discrimination and the other rights which must be met without discrimination. Second, we discuss the existing legal mechanisms used to prevent obesity, and the legal tools available to help reduce inequalities in childhood obesity. To this end, we argue that the currently favoured intervention of providing nutritional information is insufficiently effective, promotes inequalities and exacerbates discrimination. We therefore call for State implementation of restrictions on the marketing of unhealthy food to children as an evidence-based method to reduce inequalities and help better fulfil children's right to nondiscrimination and protect them from unnecessary commercial influences. In doing so, this section adds to the literature an exploration of the role of unhealthy food marketing restrictions as a tool in helping to move closer to fulfilling the child's right to nondiscrimination; which, in turn, also helps further develop the broader literature on behavioural economics $^{72}$ and the limits of consumer empowerment by information. ${ }^{73}$

\subsection{Duties of the State}

States are under an obligation to respect, protect, and fulfil ${ }^{74}$ the rights of the child and to ensure non-discrimination on the basis of socioeconomic status in the exercise of these rights. These duties are not merely passive or negative: the State must also be proactive in tackling discrimination. ${ }^{75}$ As the State cannot know the causes of discrimination without looking upstream in the causal chain to identify the factors which have contributed to discrimination, ${ }^{76}$ States are under a specific duty to monitor situations as well as to collect and analyse both systematic and disaggregated data relating to the background and circumstances of children and their families. ${ }^{77}$ Such duties may at times become obligations to take 'affirmative action in order to diminish or eliminate conditions which cause or help to perpetuate discrimination' ${ }^{78}$

More specifically, to 'respect' means to refrain from undermining children's access to healthy food. This negative approach is more adept to under-nutrition, but it does help serve to address other forms of malnutrition. For instance, access to healthy food can be hampered in school catering, where social and geographic disparities could appear in the access to nutritionally-balanced canteen menus. In France, for example, a legislative amendment was presented to Parliament for a proposed bill on equality and citizenship, which sought to make access to healthy, locally grown produce compulsory in public catering. This was based on

\footnotetext{
${ }^{72}$ Above n19.

${ }^{73}$ Above n20.

74 A Eide, 'Realization of Social and Economic Rights and the Minimum Threshold Approach' (1989) 10 Human Rights Law Journal 37.

${ }^{75}$ Committee on the Rights of the Child, 'General Comment No. 5 2003 CRC/GC/2003/5', [12].

${ }^{76}$ Above n15, 48.

${ }^{77}$ Committee on the Rights of the Child, 'General Comment No. 7 2005' CRC/C/GC/7.Rev1, [12].

${ }^{78}$ Human Rights Committee, 'General Comment No 18', 1989, HRI/GEN/1/Rev.8, [10]. See also P Alston, 'The Legal Framework of the Rights of the Child' 91(2) Bulletin of Human Rights 5. It should be noted that affirmative action must also be non-discriminatory.
} 
the right to health, with the aims of avoiding poor quality, highly processed school meals and to prevent local disparities in the diets of school children. ${ }^{79}$ While the amendment was not adopted, it illustrates the application of the right to health and nutritional discrimination as reasoning to improve childhood diets.

To 'protect', beyond simple abstention, requires States to ensure that individuals, business actors and others do not interfere with access to adequate nutrition. This implies the adoption of measures to ensure the effectiveness of the rights of children to have access to a healthy diet, and not to be affected by negative influences. States should, therefore, adopt rules to ensure that industry actors do not infringe children's fundamental right to a healthy diet. In this regard, some conflicts may surface between children's rights and economic freedoms. In particular, there is a balance to be struck between industry's freedom of commercial speech and consumers' right to health and to a healthy diet. ${ }^{80}$ In her interim report in 2016, Hilal Elver, the Special Rapporteur on Right to Food, underlined the responsibility that companies bear in order to avoid infringing human rights:

Recognizing that industry self-regulation is ineffective, Governments should impose strong regulatory systems to ensure that the food industry does not violate citizens' human rights to adequate food and nutrition. It is recognized, however, that such efforts may face formidable resistance from a food industry seeking to protect its economic interests. ${ }^{81}$

The obligation to 'fulfil' implies that States should adopt appropriate legislative, administrative, budgetary, judicial and other measures to ensure the full realization of children's human rights. While childhood obesity is complicated, and its eradication complex, reducing inequalities in childhood obesity presents further challenges. Firstly, and most fundamentally, tackling health inequalities requires a reduction in the inequalities in the distribution of socioeconomic factors, such as education and employment. Secondly, inequalities in health can be reduced by tackling intermediary determinants, such as the consumption of energy-dense diets, which mediate the effect of socioeconomic factors on health. ${ }^{82}$ While such actions should benefit all in society universally, it should be at a scale and intensity that is proportionate to the level of disadvantage. ${ }^{83}$ These actions require a comprehensive, multi-level, multi-sector, health-in-all policies approach with the backing of political will. $^{84}$

\subsection{Legal tools}

\footnotetext{
${ }^{79}$ LOI no 2017-86 du 27 janvier 2017 relative à l'égalité et à la citoyenneté, JORF no 0024 du 28 janvier 2017.

${ }^{80}$ See further, chapters by Roache and Cabrera and Garde and Byrne in this volume.

${ }^{81}$ H Elver, 'UN Special Rapporteur on the Right to Food: Report', A/71/282 3 August 2016.

${ }^{82}$ Closing the Gap in a Generation: Health Equity Through Action on the Social Determinants of Health (WHO 2008).

${ }^{83}$ 'Fair Society, Healthy Lives: Strategic Review of Health Inequalities in England' (The Marmot Review, 2010), 16.

84 'A Conceptual Framework for Action on the Social Determinants of Health' (WHO, 2010).
} 
There are many interventions, of varying effectiveness, which can contribute to reducing levels of childhood obesity, including increasing physical activity, school-based education programmes or improving medical treatment. ${ }^{85}$ Some interventions even achieve some, but often limited, effectiveness in reducing inequalities in childhood obesity. ${ }^{86}$ While no single intervention will prevent or reverse childhood obesity and its inequalities, of the options available to the State at individual, community and societal levels, States have mostly opted for empowering consumers and parents through mandatory food information. ${ }^{87}$ Consumer empowerment through information rests on the idea that if individuals are provided with sufficient, accurate information they will become well-informed; and well-informed consumers will make rational, healthy decisions in food purchasing and consumption decisions. $^{88}$

Such policies transfer responsibility from the State, which decides the type and method of information consumers are given, to the consumer, who becomes responsible for making healthy food decisions. This is problematic as childhood obesity is heavily influenced by upstream factors which the child cannot influence. Influence over the environment in which the child lives, and the decisions they are able to take, are limited. Indeed, nutritional information is not an intervention aimed at all children due the child's limited cognitive capacity. This weak position of children in society has been reinforced by the CRC Committee. ${ }^{89}$ Moreover, not only does this transfer of responsibility not take into account the wider context, it assumes that obesity is exclusively a matter of personal or family responsibility. ${ }^{90}$

This approach does have some economic and equitable advantages - such as correcting informational asymmetries which favour industry, and helping to fulfil the consumer's right to information. ${ }^{91}$ However, it has been strongly criticized as an ineffective tool. ${ }^{92}$ Moreover, not only are these policies insufficient to reduce obesity in all groups of consumers, they are

\footnotetext{
${ }^{85}$ E Waters et al, 'Interventions for Preventing Obesity in Children' (2011) Cochrane Database Systematic Reviews; CD Summerbell et al, 'Evidence-Based Recommendations for the Development of Obesity Prevention Programs Targeted at Preschool Children' (2012) 13(1) Obesity Reviews 129.

${ }^{86}$ CL Bambra et al, 'How Effective are Interventions at Reducing Socioeconomic Inequalities in Obesity Among Children and Adults? Two Systematic Reviews' (2015) 3(1) Public Health Research; N Freudenberg, 'Commentary: Reducing Inequalities in Child Obesity in Developed Nations: What Do We Know? What Can We Do?’ (2013) 31(1) Revista Portugesa de Saude Publica 115.

${ }^{87}$ A Alemanno and A Garde, 'The Emergence of An EU Lifestyle Policy: The Case of Alcohol, Tobacco and Unhealthy Diets' (2013) 50(6) Common Market Law Review 1745.

${ }^{88}$ M Friant-Perrot and A Garde, 'From BSE to Obesity: EFSA's Growing Role in the EU's Nutrition Policy' in A Alemanno and S Gabbi, Foundations of EU Food Law and Policy: Ten Years of the European Food Safety Authority (Routledge, 2014).

${ }^{89}$ Above n77, [11(b)].

${ }^{90}$ See for instance: DB Resnik, 'Responsibility for Health: Personal, Social, and Environmental' (2007) 33(8) Journal of Medical Ethics 444; C Newdick, 'Health Equality, Social Justice and the Poverty of Autonomy' (2017) 12 Health Economics, Policy and Law 411.

${ }^{91}$ I Ramsay, 'Framework for Regulation of the Consumer Marketplace' (1985) 8 Journal of Consumer Policy 353.

${ }^{92}$ Such critiques have been made many times in the broader consumer law and economics literature - see above n20.
} 
particularly ineffective for members of lower socioeconomic position groups and thus tend to promote inequalities. ${ }^{93}$ This is for three reasons.

Firstly, the assumption that consumers are given sufficient, accurate information which is not misleading is not always true. For instance, whereas many consumers would prefer to also receive nutritional information per portion of food, this is rarely mandatory. Similarly, a product labelled with a health claim, such as 'low in fat', may nonetheless have an overall unhealthy nutritional profile. Members of lower socioeconomic groups suffer worse from this assumption as, for instance, the most vulnerable consumers are often less able to understand nutritional information and health messages. ${ }^{94}$

Secondly, research in behavioural economics has brought to the fore the identification of two sets of systems of cognitive function. ${ }^{95}$ Whereas most consumers make the vast majority of decisions relating to food using their brain's automatic system - which is effortless and fast but uncontrolled, emotional and engages superficially - information policies assume that consumers use their brain's reflective system - which is controlled, effortful and engages deeply, but is slow and has limited capacity. ${ }^{96}$ This research reveals that consumers rarely act completely rationally, not least because consumers are subject to heuristics and biases. For instance, consumers do not always perceive nutritional information. Moreover, because of their circumstances, members of lower socioeconomic groups tend to be subject to greater limitations of both these types of cognitive systems. For instance, poverty causes psychological consequences, including stress and negative affective states, which lead to short-sighted and risk-averse decision-making, which reinforce habitual behaviours more strongly. ${ }^{97}$ Similarly, poorer members of society will more often have to make decisions which require volition - this draws on finite psychological resources, so that earlier acts to maintain willpower for healthy decisions will have detrimental impacts on later attempts at volition. $^{98}$

Thirdly, rationality is not the sole determinant of consumer behaviour, and the consumer's environment can result in purchasing decisions which are not in the consumer's best health interests. Again, this becomes more difficult with members of lower socioecomoinc groups. For instance, consumers may not be able to follow through with healthy decisions if their poverty means that purchasing is restricted by cost, as unhealthy energy-dense food is often cheaper. ${ }^{99}$

\footnotetext{
${ }^{93} \mathrm{~N}$ Gokani, 'Regulation for Health Inequalities and Non-Communicable Diseases: In Want of (Effective) Behavioural Insights' (2018) 24(6) European Law Journal 490.

${ }^{94}$ KG Grunert and JM Wills, 'A Review of European Research on Consumer Response to Nutrition Information on Food Labels' (2007) 15(5) Journal of Public Health 385; S Campos et al, 'Nutrition Labels on Pre-Packaged Foods: A Systematic Review' (2011) 14(8) Public Health Nutrition 1496.

${ }^{95}$ Above n19.

96 'Mindspace' (Institute for Government, 2010).

97 J Haushofer and E Fehr, 'On the Psychology of Poverty' (2014) 344 Science 862.

98 RE Baumeister et al, 'Ego Depletion: Is the Active Self a Limited Resource?' (1998) 74(5) Journal of Personality and Social Psychology 1252.

${ }^{99}$ A Drewnowski and SE Specter, 'Poverty and Obesity: The Role of Energy Density and Energy Costs' (2004) 79(1) American Journal of Clinical Nutrition 6; A Drewnowski, 'Obesity and the Food Environment: Dietary Energy Density and Diet Costs’ (2004) 27(3) American Journal of Preventative Medicine 154.
} 
To overcome some of the limits in empowering consumers through information, these polices need to be placed within a broader strategy. To this end, restricting the marketing of unhealthy food to children offers an evidence-based intervention to reduce obesity for all children. ${ }^{100}$ There is unequivocal evidence linking unhealthy food marketing to childhood obesity, ${ }^{101}$ and increasing recognition that such marketing has a negative impact on children and the enjoyment of their rights. Moreover, as a group, children do not have the necessary cognitive capacity to identify the persuasive intent of advertising, and therefore marketing can manipulate behaviour through implicit persuasion, which may, in turn, explain why cognitive defences would not even protect older children. ${ }^{102}$

The WHO Set of Recommendations on the Marketing of Foods and Non-Alcoholic Beverages to Children ${ }^{103}$ fleshes out the provisions that States should adopt to comply with their obligations under the CRC, which were unanimously adopted by the World Health Assembly in May 2010. ${ }^{104}$ The WHO has published a framework implementation report ${ }^{105}$ to provide technical support to States in implementing the Recommendations and in monitoring and evaluating their implementation. Despite repeated calls on States, ${ }^{106}$ they remain poorly implemented to date. ${ }^{107}$ These Recommendations should be seen as a guide for actions that States should consider in order to end childhood obesity and empower children and their parents and families. As such, they have the potential to support a children's rights-based approach to obesity prevention, even though they do not specifically refer to children's rights.

Given that calorie consumption, rather than decrease in physical activity, appears to be the main driving force behind the growing obesity epidemic, ${ }^{108}$ implementing the WHO Recommendations will reduce the preference, purchase requests and consumption of

\footnotetext{
${ }^{100}$ A Child Rights-Based Approach to Food Marketing: A Guide for Policy Makers (UNICEF, 2018); A Garde, N Gokani and M Friant-Perrot 'Children's Rights, Childhood Obesity and Health Inequalities' (2018) 43 UNSCN News 65; A Garde, S Byrne, N Gokani and B Murphy, 'For A Children's Rights Approach to Obesity Prevention: The Key Role of Effective Implementation of the WHO Recommendations' (2017) 8(2) European Journal of Risk Regulation 327.

${ }^{101}$ EJ Boyland and M Tatlow-Golden, 'Exposure, Power and Impact of Food Marketing on Children: Evidence Supports Strong Restrictions' (2017) 8(2) European Journal of Risk Regulation 224.

${ }^{102}$ A Nairn and C Fine, 'Who's Messing With My Mind? The Implications of Dual-Process Models for the Ethics of Advertising to Children' (2008) 27(3) International Journal of Advertising 447; JL Harris, KD Brownell and JA Bargh, 'The Food Marketing Defense Model: Integrating Psychological Research to Protect Youth and Inform Public Policy' (2009) 3(1) Social Issues and Policy Review 211.

${ }^{103}$ WHO Set of Recommendations on the Marketing of Foods and Non-Alcoholic Beverages to Children (WHO, 2010).

${ }^{104}$ World Health Assembly, 'Resolution 63/14' (2010).

${ }^{105}$ A framework for implementing the set of recommendations on the marketing of foods and non-alcoholic beverages to children (WHO, 2012).

${ }^{106}$ Global Action Plan for the Prevention and Control of Noncommunicable Diseases 2013-2020 (WHO, 2013); Final Report of the WHO Commission on Ending Childhood Obesity (WHO, 2016).

${ }^{107}$ VI Kraak et al, 'Progress Achieved in Restricting the Marketing of High-Fat, Sugary and Salty Food and Beverage Products to Children' (2016) 94(7) WHO Bulletin 540; A Garde and G Xuereb, 'The WHO Recommendations on the Marketing of Food and Non-Alcoholic Beverages to Children' (2017) 8 European Journal of Risk Regulation 211.

${ }^{108}$ BA Swinburn et al, 'The Global Obesity Pandemic: Shaped by Global Drivers and Local Environments' (2011) 378(9793) Lancet 804; P Scarborough et al. 'Increased Energy Intake Entirely Accounts for Increase in Body Weight in Women But Not in Men in the UK between 1986 and 2000' (2011) 105(9) British Journal of Nutrition 1399.
} 
unhealthy food by all children. Yet it will have greater positive impacts on children from lower socioeconomic groups, and thus help towards reducing inequalities in childhood obesity. This is because the Recommendations call on States to adopt policies to tackle the two main components of marketing: the exposure (reach and frequency) and power (creative content, design and execution) of the marketing - both of which have a greater negative impact on children from socioeconomic groups associated with calorie-dense diets.

This is because children tend to be exposed to marketing more than adults. ${ }^{109}$ Moreover, children from a lower socioeconomic status tend to be exposed to greater degrees of marketing, ${ }^{110}$ as shown in relation to many media, including television, ${ }^{111}$ magazines, ${ }^{112}$ outdoor advertising ${ }^{113}$ and placement of fast-food outlets. ${ }^{114}$ Such marketing is often specifically targeted towards these groups, ${ }^{115}$ and thereby amplifying their pre-existing vulnerabilities. This becomes even more of a concern because digital marketing methods can target children with precision. ${ }^{116}$ Moreover, children are also more susceptible to unhealthy food marketing than adults. This inflated susceptibility to marketing is further amplified for children of a lower socioeconomic status, including children from lower- and middle-income countries. ${ }^{117}$ It has been found, for example, that these children tend to make changes to their food preferences after only brief exposure to marketing. ${ }^{118}$ Furthermore, obese children - who may already have been negatively impacted by unhealthy food marketing - are also more susceptible to such marketing than non-overweight children. ${ }^{119}$ In the words of Anand Grover, then UN Special Rapporteur on the Right to Health: 'States have a positive duty to regulate unhealthy food advertising and the promotion strategies of food companies. Under the right to

\footnotetext{
${ }^{109}$ See for example: ME LoDolce et al, 'Sugar as Part of a Balanced Breakfast? What Cereal Advertisements Teach Children about Healthy Eating' (2013) 18(11) Journal of Health Communication: International Perspectives 1293.

${ }^{110}$ See for example: SA Grier and S Kumanyika, 'Targeted Marketing and Public Health' (2012) 31(21) Annual Review of Public Health 349.

111 J Adams et al, 'Socio-Economic Differences in Exposure to Television Food Advertisements in the UK: A cross-sectional study of advertisements broadcast in one television region' (2012) 15(3) Public Health Nutrition 487.

${ }^{112}$ See for example: J Adams and M White, 'Socio-Economic and Gender Differences in Nutritional Content of Foods Advertised in Popular UK Weekly Magazines’ (2009) 19(2) European Journal of Public Health 144.

113 Jean Adams et al, 'Socio-Economic Differences in Outdoor Food Advertising in a City in Northern England' (2011) 14(6) Public Health Nutrition 945.

${ }^{114}$ KE Smoyer-Tomic et al, 'The Association between Neighborhood Socioeconomic Status and Exposure to Supermarkets and Fast Food Outlets' (2008) 14(4) Health \& Place 740.

115 Above n110.

${ }^{116}$ KC Montgomery, 'Youth and Surveillance in the Facebook Era: Policy interventions and social implications' (2015) 39(9) Telecommunications Policy 771.

${ }^{117}$ G Cairns et al., 'Systematic Reviews of the Evidence on the Nature, Extent and Effects of Food Marketing to Children: A retrospective summary' (2013) 62(1) Appetite 209; SA Lear et al, 'The Association Between Ownership of Common Household Devices and Obesity and Diabetes in High, Middle and Low Income Countries' (2014) 186(4) Canadian Medical Association Journal 258.

${ }^{118}$ S Kumanyika and S Grier, 'Targeting Interventions for Ethnic Minority and Low-Income Populations', (2006) 16(1) The Future of Children 187.

119 JC Halford et al, 'Beyond-Brand Effect of Television (TV) Food Advertisements/Commercials on Caloric Intake and Food Choice of 5-7-Year-Old Children’ (2007) 49 Appetite 263.
} 
health, States are especially required to protect vulnerable groups such as children from violations of their right to health. ${ }^{120}$

\section{Conclusion}

Despite efforts in tackling childhood obesity, benefits have not been experienced equally everywhere or by everyone. The widespread, entrenched inequalities in childhood obesity between and within societies reflect the differences in the conditions in which communities live. These health inequalities are systematic, socially produced and unfair: they are caused by the unequal distribution of socioeconomic resources. They are unnecessary and unjust, and they offend against the human rights of children and their families. Corrective action is required as a matter of social justice to restore children's autonomy, dignity and freedom in food choices.

These are not newly-discovered concerns. From the Alma-Ata Declaration of $1978^{121}$ and the Vienna Declaration of $1993^{122}$ to the Rome Declaration on Nutrition of $2014,{ }^{123}$ national and international actors have envisioned the eradication of inequalities in food provision and called for a global response to end all forms of malnourishment, including obesity. What is required is 'coordinated action among different actors, across all relevant sectors at international, regional, national and community levels...supported through cross-cutting and coherent policies, programmes and initiatives, including social protection, to address the multiple burdens of malnutrition and to promote sustainable food systems, ${ }^{124}$ through reinforcing the idea that 'the progressive realization of the right to adequate food in the context of national food security is fostered through sustainable, equitable, accessible in all cases, and resilient and diverse food systems'. ${ }^{125}$

In order to provide greater attention to the under-researched issues of inequalities in childhood obesity, discrimination and equality - and to build on the normative impetus for more effective State intervention and to better understand the correct role of the State - this chapter has added depth to the theorization of inequalities in childhood obesity through the lens of human rights. An approach grounded in human rights increases accountability, by holding stakeholders to their commitments; increases legitimacy, as human rights derived from international treaties are universally recognised, inalienable international standards; and provides an advocacy tool to help galvanize political will.

\footnotetext{
${ }^{120}$ A Grover, 'Unhealthy foods, non-communicable diseases and the right to health. Report of the Special Rapporteur on the right of everyone to the enjoyment of the highest attainable standard of physical and mental health', 2014, United Nations Document A/HRC/26/31. United Nations Human Rights Council, 11.

${ }^{121}$ Declaration of Alma-Ata International. Adopted by the Conference on Primary Health Care in Alma-Ata on 6-12 September 1978.

${ }^{122}$ Vienna Declaration and Programme of Action. Adopted by the World Conference on Human Rights in Vienna on 25 June 1993.

${ }^{123}$ Rome Declaration on Nutrition. Adopted by the Second International Conference on Nutrition in Rome on 19-21 November 2014.

${ }^{124}$ Ibid.

${ }^{125}$ Above $\mathrm{n} 123$.
} 
While the existing literature has drawn connections between health inequalities and human rights generally ${ }^{126}$ or other specific rights, ${ }^{127}$ and developed the right to non-discrimination broadly $^{128}$ or in relation to other concerns, ${ }^{129}$ this chapter has progressed the research by deepening the understanding of the link between health inequalities and the right to nondiscrimination. ${ }^{130}$ Moreover, it has provided a fresh view by seeking to demonstrate that the right to non-discrimination - and the rights to food and health, and to their exercise by children without discrimination on the basis of socioeconomic status - impose binding legal commitments on States to fulfil equality of opportunity in childhood nutrition. It has further argued that these duties place obligations on States to create environments which grant all children the capacity to choose healthy food and therefore reduce the prevalence of obesity.

Furthermore, as States continue to rely on ineffective policies which fail to sufficiently reduce childhood obesity and can even increase inequalities, this chapter has further argued that, in the exercise of rights to health and to adequate food, an approach grounded in the child's right to non-discrimination (as interpreted in this chapter) strengthens the capacities of children (as right-holders) to realize their rights and of States (as duty-bearers) to meet their legal obligations under the CRC and other binding human rights documents. It has, therefore, built on the broader literature on behavioural economics ${ }^{131}$ and consumer information ${ }^{132}$ to show that current mechanisms of obesity prevention, mainly nutritional declarations, are insufficiently effective and perpetuate inequalities; and introduced the idea that these measures therefore propagate discrimination. By demonstrating that the implementation of restrictions on unhealthy food marketing to children will help States move closer to fulfilling of the child's right to non-discrimination in the CRC, this chapter strengthens calls for such restrictions. ${ }^{133}$ Of the many tools available to States, such restrictions are effective evidencebased opportunities to help fulfil the State's obligations to improve nutrition, reduce obesity and other related non-communicable diseases and increase well-being for every child and particularly the most vulnerable children.

\footnotetext{
${ }^{126}$ Above n13.

${ }^{127}$ Above n14.

${ }^{128}$ Above n15.

${ }^{129}$ See for instance: Karien Stronks et al, 'Social justice and human rights as a framework for addressing social determinants of health Final report of the Task group on Equity, Equality and Human Rights Review of social determinants of health and the health divide in the WHO European Region' (WHO, 2016) <http://www.euro.who.int/_data/assets/pdf_file/0006/334356/HR-task-report.pdf>.

${ }^{130}$ Above n18.

${ }^{131}$ Above $n 19$.

${ }^{132}$ Above n20.

${ }^{133}$ Above n12.
} 